Social gain: Is corporate social responsibility enough?

Sharyn R Rundle-Thiele

Australasian Marketing Journal; Nov 2009; 17, 4; ABI/INFORM Global pg. 204

\title{
Social gain: Is corporate social responsibility enough?
}

\author{
Sharyn R. Rundle-Thiele * \\ Griffich University, Griffith Business School, Deportment of Marketing, Nathan, Qld 4111, Australia
}

\section{A R TICLE IN FO}

\section{Keywords:}

Corporate social responsibility

Corporate social performance

Alcohol

Observations

Social change

\begin{abstract}
A B S T R A C T
This paper considers whether the concept of corporate social responsibility (CSR) is sufficient for social behavioural change. Two data sources are used to consider whether alcohol is enjoyed responsibly in Australia by informed adults. First, 582 surveys were analysed to consider whether respondents were adequately informed about alcohol. Second, covert observations were used to record what people actually drink to understand whether alcohol is always enjoyed responsibly. Taken together, the results suggest many adults are not adequately informed and many Australian adults do not enjoy alcohol responsibly. A more rigorous social responsibility approach may be warranted. To achieve sustained behavioural change companies need to move towards corporate social performance (CSP). CSP requires CSR interventions to be evaluated to determine their contribution towards real social gains. CSR is not enough to reach the social goals required by society. The concept of CSP takes away the lip service around CSR by requiring companies to document sustained behavioural change.
\end{abstract}

2009 Australian and New Zealand Marketing Academy. All rights reserved.

\section{Introduction}

Since the Rudd Government was elected in late 2007 alcohol has been placed on the national agenda. The widely publicised "Alcopop tax" introduced in the 2008 May Budget was claimed to be a direct Government measure designed to reduce demand for ready to drink spirits (RTD's) favoured by Australia's youth who often drink to excess (termed binge drinking). At the time of writing this article the Australian Government was considering revising Australian Drinking Guidelines (NHMRC, 2001) to lower the recommended number of standard drinks recommended for Australian adults. The draft recommendations, currently being considered by the Australian Government, recommend that men and women should drink two standard drinks or less in any one day (NHMRC 2007). The Australian alcohol industry provides an ideal case in point to consider whether the concept of corporate social responsibility is sufficient to bring about social change.

The explosive growth in the demand for ratings of corporate social responsibility (CSR) has resulted in a marked increase in the number of groups supplying CSR ratings to investors and consumers (Marquez and Fombrun, 2005, p. 304). These ratings have become so important that many large corporations now appoint in house specialists and teams to monitor and communicate their social responsiveness. Fosters Group Limited, one key player in the Australian alcohol industry, is an Australian social responsibility leader according to two key CSR ratings, namely the Australian Corporate Responsibility and FTSE4Good Indices. In their 2007 Sustainability Report Fosters Group Limited report a wide range of so-

\footnotetext{
* Tel.: +61734704539 .

E-mail address: rundle@usq.edu.du
}

cially responsible policies and practices, under the key headings of workplace (employees), health, safety and environment, community and market. Using current corporate social responsibility thinking we are left with no room for doubt that Fosters Group Limited is a socially responsible corporation.

This paper contends it is time to move academic debate from social responsibility where discussions have centred upon considering how companies should be responsible and to whom; towards social performance, which would require companies to articulate the contribution of CSR interventions have made towards real social gains, e.g. a reduction in binge drinking. This paper uses the notion of responsible alcohol consumption to reflect on whether being socially responsible is enough for companies.

\section{Literature review}

One of the best-known Corporate Social Responsibility (CSR) models is Carroll's $(1991,1999)$ CSR pyramid, which presents company responsibilities using four key dimensions. According to this model businesses are expected to be profitable, obey the law, be ethical, and to be good corporate citizens (Carroll's, 1991, 1999). Corporate social responsibility refers to an organisations obligation to use their resources in ways that protect and benefit society, and ensures they generate equitable and sustainable benefits for stakeholders (Graafland and van de Ven, 2006; Mikkila, 2003). Many companies have adopted corporate social responsibility strategies in response to the recognised moral and ethical obligations.

Carroll's (1991, 1999) CSR pyramid presents company's social obligations as comprising economic, legal, ethical and philanthropic responsibilities. Carroll (1991) noted that businesses were created 
as economic entities driven by a profit motive, thus economic performance underpins the other three CSR components. Legal responsibility involves businesses complying with federal, state and local government laws and regulations (Carroll, 1991). This was followed by ethical responsibilities, those standards, norms and expectations that reflect a concern for what consumers, employees, shareholders and the community regard as fair, just and respectful of stakeholders' moral rights (Carroll, 1991). Finally. philanthropic responsibility was the expectation that businesses be good corporate citizens. actively engaging in programs to promote human welfare and goodwill (Carroll, 1991).

There are many benefits arising from corporate social responsibility (CSR) for companies, including increased profits, customer loyalty, trust, positive brand attitude, satisfaction, word of mouth and combating negative publicity (e.g., Barone et al., 2000; Berger and Kanetkar, 1995; Brown and Dacin, 1997; Creyer and Ross, 1997; Drumwright, 1996; Luo and Bhattacharya, 2006: Maignan and Ferrell, 2001, 2004: Murray and Vogel, 1997: Sen and Bhattacharya, 2001; Sen et al., 2006). For example, CSR contributes positively to market value, partially through customer satisfaction. Luo and Bhattacharya (2006) calculated that, for a typical company in their sample with an average market value of $\$ 48$ billion, a one unit increase in CSR ratings resulted in approximately $\$ 17$ million more profits on average in subsequent years. There is little doubt that corporate social responsibility benefits companies.

CSR is essentially a social contract requiring commitment to behave in an ethical and responsible manner, to 'minimise the negative impacts and maximise the positive impacts' (Maignan and Ferrell, 2004) on issues important to stakeholders (Moir, 2001). Consensus is emerging that companies are responsible to stakeholders. However, the nature, degree and scope of CSR, continues to be debated by academic researchers. For example, Lantos (2001) considers that companies must be economically, legally and ethically responsible but not philanthropically responsible. This view is supported by others. Consider Blythe (2006) who states "societal marketing is a lovely idea but one which might be difficult to push through at a board meeting". The views of these authors are contrary to others (e.g. Carroll, 1979; Mascarenhas, 1995) who argue that in addition to economic, legal and ethical responsibilities, companies must be responsible to society as whole. A further grey area in the academic literature relates to stakeholders, with researchers debating who exactly companies should be beholden to. For example, some researchers (Brown and Dacin, 1997; Kotler and Lee, 2005) define CSR with respect to the general community or society, while other researchers (Craig Smith, 2003; Maignan and Ferrell, 2004) restrict their audience for CSR to corporate stakeholders, including affected local communities.

There is little doubt that both practising marketers and academics recognise the importance of corporate social responsibility. The central focus of academic tebate remains centred upon distinguishing between different types of CSR programs (examples include Bhattacharya and Sen, 2004; Kotler and Lee, 2005), understanding the positive impacts of CSR initiatives (Lafferty and Goldsmith, 2005; Lichtensetein et al., 2004; Sen et al., 2006) and what constitutes CSR (Carroll, 1979; Lantos, 2001; Mascarenhas, 1995). Less attention has been directed towards understanding whether the socially responsible policies and programs reported by corporations are actually protecting and benefiting society. The notion of corporate social performance (CSP) was first introduced by Wood (1991). Her central idea was to consider whether there was any response to socially responsible programs and policies. Wood (1991) recommended giving consideration to the outcomes of corporate behaviour (for example social impacts) rather than focussing on the corporate behaviour itself.
While the notion of CSP has been introduced for some time there has been little focus on understanding whether CSR initiatives are effective. As noted by Redmond and Griffith (2006, p. 753) "the ultimate goal for social marketing initiatives is sustained behavioural change." Companies need to evaluate the effectiveness of CSR initiatives to understand their effectiveness. There is a considerable body of evidence (see NHMRC, 2007 who provide an extensive overview based on a literature review of health and allied literatures) suggesting that sustained high alcohol consumption increases risk of disease, accidents and death. Reports indicate that more Australians are consuming alcohol at risky/high levels than ever before (ABS, 2006a). At present in Australia there are too many Australian adults choosing to drink too much alcohol and the cost of this behaviour to the Australian community is an estimated $\$ 15$ billion per annum. Australian Government statistics (e.g. ABS 2006a; NHMRC 2007) suggest that sustained change in alcohol consumption in Australia is required.

This paper takes a corporate social performance viewpoint, exploring Australians" knowledge of alcohol and observing drinking behaviour. To be adequately informed and hence able to choose to drink responsibly, people would need to understand what constitutes low/moderate and finally high levels of alcohol consumption. If people are not sufficiently aware of risky consumption levels they are inadequately equipped to make informed decisions about safe levels of alcohol use and this would suggest that marketers may not be meeting their social responsibility obligations.

\section{Methodology}

Two methods were selected for this study permitting the responsible drinking of alcohol to be viewed through two lenses. Covert observations were used in this research to observe whether people enjoyed alcohol responsibly while drinking out of home. The rationale for using observations to supplement the survey method was that observations can be used to record phenomena with "the least response bias of any market research methodology" and by utilising observations it is possible to "record what consumers actually do, not what they claim to have done" (Boote and Mathews, 1999, p. 20). Consistent with prior research (examples include AlHW, 2005: Baum, 2000; Reis and Riley, 2002) surveys were chosen to understand how adequately Australians are informed about alcohol to determine whether Australians are able to make informed decisions about safe levels of alcohol use.

\section{Study one - surveys}

A convenience sample was chosen for this exploratory research as this sampling method is not as costly as random sampling methods (Pride et al., 2006). Eight hundred surveys were distributed to a combination of friends, relatives, work colleagues and students on campus. The cover letter and front page of the survey highlighted that respondents needed to be 18 years or older. The survey contained two sections.

The first section contained 16 questions to assess what Australians knew about alcohol consumption levels, drink driving limits and the number of standard drinks contained in popular alcoholic beverages. Consumers were asked to nominate safe, risky, high risk and binge drinking levels for males and females, the number of drinks that males and females can drink in the first hour and subsequent hours and the number of standard drinks contained in three different types of alcoholic beverages. Answers were considered to be correct and were awarded a score of 1 if the respondent provided a correct answer or an answer that was lower than the correct answer. Information on drinking levels was obtained from 
Table 1

Comparison between 2006 census data and sample ( $n=582$ ).

\begin{tabular}{|c|c|c|c|c|c|c|c|}
\hline Age & Sample (\%) & $\operatorname{ABS}($ (x) & Gender & Sample (\%) & $\operatorname{ABS}(\%)$ & Level of Education & Sample (\%) \\
\hline $18-24$ & 56.6 & 13.3 & Male & 49.9 & 49 & Ptimary school & 0.9 \\
\hline $25-34$ & 15.5 & 16.8 & Female & 50.1 & 51 & Did not complete high school & 3.4 \\
\hline $35-44$ & 8.2 & 18.7 & & & & High school & 37.7 \\
\hline $45-54$ & 8.9 & 17.8 & & & & Diploma & 10.8 \\
\hline \multirow[t]{2}{*}{$55+$} & 10.8 & 33.4 & & & & University degree & 33.7 \\
\hline & & & & & & Post-graduate degree & 13.5 \\
\hline Merital status & Sample (\%) & $\operatorname{ABS}(\%)$ & Household size & Sample (\%) & $\operatorname{ABS}(\%)$ & Annual personal income SAIJD & Sample (X) \\
\hline Single & 60.9 & 33.2 & 1 & 9.8 & 24.3 & Less than $\$ 35,000$ & 66.1 \\
\hline Married & 33.8 & 49.6 & 2 & 24.7 & 34.1 & $\$ 35,000-\$ 44,000$ & 7.9 \\
\hline Divorced/separated & 1.6 & 11.3 & 3 & 22.7 & 15.7 & $\$ 45,000-\$ 54,000$ & 6.5 \\
\hline \multirow[t]{6}{*}{ Widow/widower } & 3.7 & 5.9 & 4 & 22.7 & 15.7 & $\$ 55,000-\$ 64,000$ & 5.0 \\
\hline & & & 5 & 19.5 & 6.8 & $\$ 65,000-\$ 74,000$ & 3.2 \\
\hline & & & 6 or more & 0.6 & 3.4 & $\$ 75,000-\$ 84,000$ & 2.7 \\
\hline & & & & & & $\$ 85.000-\$ 94,000$ & 1.1 \\
\hline & & & & & & $\$ 95,000-\$ 104,000$ & 2.2 \\
\hline & & & & & & $\$ 105,000$ and over & 53 \\
\hline
\end{tabular}

A Personal income and education categories used in this research were not consistent with ABS 2006 Census categories. Direct comparison was not possible.

NHMRC guidelines (2001). The final section collected demographic data, along with two questions asking consumers to nominate the number of alcohol drinks consumed per week and per day.

Participation in the survey was voluntary and an incentive draw offering participants a 1 in 100 chance of winning a cash prize was offered to encourage response. The total number of surveys returned was 582 , which represents a response rate of $73 \%$, which was deemed acceptable. According to (Sitzia and Wood, 1998) in the late 1990s response rates for face to face approaches were typically $77 \%$.

\section{Study two - covert observations}

Observations were chosen for the second stage of this research (Boote and Mathews, 1999) and ethical clearance was obtained to observe a public behaviour in a public place. The method of collecting observations was not complicated. It is important to note that the researchers were acutely aware that the entire description of what was to be observed could not be recorded (Rust, 1993; Kellehear, 1993). Record sheets were developed to ensure that observers could record key behaviours and consumer characteristics.

Behaviours observed included the number of drinks consumed, the type (brand) and size of alcohol drinks ordered, whether the person was in a shout, along with many of the persons activities while on premise. The brands chosen and drink size were used to calculate the number of standard drinks consumed. Where the brand of beer poured could not be observed light beer levels were used to calculate standard drinks. The lowest alcohol levels were chosen to avoid over stating. Key consumer characteristics observed involved recording the persons' gender, the number of people the person was with, whether a child was present, and finally their dress.

Observations were conducted in seven different venues in Queensland and the ACT, with observations occurring between January 2 nd and January 11 th, 2008. People were observed on various days and times of the week. People were observed in licensed premises including cafes, restaurants, wine bars, sports bars and night clubs. Venues were selected to enable maximum diversity to be achieved in a short time frame. Managers agreed to permit observation research, after they had been advised that the (unobtrusive) observations would not hinder normal business practice or their customers.

The observers sat at the venue and recorded partial and complete episodes. An episode was complete when the person was observed entering and exiting the premise. An episode was deemed to be partial when a person was not observed from entry to exit, e.g. some people were present at the time of observers' arrival or the observer left the premise before the consumer. Once again the recording of partial episodes avoids over stating the number of standard drinks consumed. Therefore, the data presented in this paper is on the conservative side. Episodes ranged from as little as $2 \mathrm{~min}$ to as much as $4 \mathrm{~h}$ and $18 \mathrm{~min}$. In all, 507 people were observed in this research with group sizes observed averaging 4.7 people and episode lengths averaging $1 \mathrm{~h}$ and $6 \mathrm{~min}$.

Multiple regression analysis was used to consider whether the number of standard drinks consumed could be predicted from a range of variables including duration, time of day, smoking and the amount of water consumed. Multiple regression analysis is the appropriate method of analysis because the number of standard drinks consumed was a single metric dependent variable. which may be related to other key variable (see Hair et al., 2006). $T$-tests were conducted to ascertain whether there were differences between the behaviours observed for different groups.

\section{Study one results - surveys}

The sample characteristics for Study 1 are reported in Table 1 along with ABS 2006 Census Data to permit comparison between the convenience sample and the Australia population. In this sample $50 \%$ were male, $61 \%$ were single and $34 \%$ were married. The household size was slightly higher (3.2) in this sample when com-

\section{Table 2}

Self reported average daily alcohol consumption $(\pi-582)$.

\begin{tabular}{ll}
\hline Average no. of drinks reporteda & Proportion of people surveyed (\%) \\
\hline 0 & 49.2 \\
1 & 29.1 \\
2 & 12.2 \\
Men and women should drink two standard drinks \\
\multicolumn{2}{l}{ or less in any one day (NHMRC 2007) } \\
3 & 4.8 \\
4 & 1.5 \\
5 & 0.9 \\
6 & 1.6 \\
7 & 0.2 \\
8 & 0.2 \\
9 or more & 0.6
\end{tabular}

"This data should be treated with caution as respondents were not asked to report the number of standard drinks. 
Table 3

Proportion of respondents who answered the question correctly. ${ }^{d}$

\begin{tabular}{ll}
\hline Statement & $\begin{array}{l}\text { Proportion stating correct } \\
\text { answer or less (\%) }\end{array}$ \\
\hline A $750 \mathrm{ml}$ bottle of wine (12\% Ale/Vol) contains 7 or & 25.1 \\
more standard drinks & \\
A $375 \mathrm{ml}$ full-strength beer (4.9\% Alc/Vol) & 45.1 \\
Contains 1.5 standard drinks & \\
A $30 \mathrm{ml}$ spirit nip (40\% Alc/Vol) is 1 standard drink & 83.2 \\
The legal blood alcohol limit for drink driving is & 75.4 \\
$\quad$ 0.05 &
\end{tabular}

${ }^{1}$ Respondents who provided an answer that was lower than or matched the correct response were considered to have answered the question correctly.

pared with the national average (2.5). Fifty six percent of the sample was aged between 18 and 24 years and approximately $20 \%$ of the sample was aged over 45 years. Two thirds of the respondents had personal annual income of $\$ 35,000$ or less. The sample was younger, single, living in smaller households, and more highly educated when compared with 2006 ABS census data (ABS 2006b).

Respondents were asked to report the number of alcoholic drinks they would have on average each day and this is now summarised in Table 2.

One half of respondents reported they consume 0 alcoholic drinks a day on average. One in ten respondents reported daily amounts that indicate they were drinking at risky or high risk levels. The rates reported for risky and high risk drinking by respondents in this sample were lower than rates reported by the Australian Bureau of Statistics (2006a). ${ }^{1}$

The second section of the survey comprised a total of 16 items, to gather information on the respondents' knowledge of alcohol consumption levels, standard drinks and legal drink driving limits. Less than $3 \%$ of respondents answered all questions correctly. These results suggest there are "knowledge gaps". Approximately one in three respondents were between $75 \%$ and $100 \%$ correct. These results suggest that two in three respondents were not armed with sufficient knowledge to make informed decisions about the amount of alcohol they are consuming.

The proportion of respondents answering each question correctly was considered next to understand the "knowledge gaps". The proportion of respondents answering each item correctly is reported in Tables 3-5.

While the majority of respondents knew the legal blood alcohol limit for driving in Australia, three-quarters of respondents did not know that a standard $750 \mathrm{ml}$ bottle of wine contains 7 or more standard drinks and more than one-half of respondents did not know that a $375 \mathrm{ml}$ full-strength beer (4\% alcohol) contained 1.5 standard drinks. These findings are consistent with research conducted in the early 1990s by Carruther and Binns (1992) and also by Lader and Goddard (2006). Carruther and Binns (1992) identified that the level of knowledge of the alcohol content in a variety of beverages and the knowledge of the term 'standard drink' was poor. While the Lader and Goddard (2006) study identified that $58 \%$ of respondents knew the correct standard drink serving size for beer in the UK. These data indicate that consumers may not be sufficiently informed.

Most respondents knew the levels associated with low risk alcohol consumption for males. One in two respondents did not know that males binge drink when they drink seven or more standard drinks on any single occasion and approximately one in five respondents did not know how much males can consume in the first hour to avoid exceeding legal blood alcohol limits.

\footnotetext{
1 ABS data relies on self report data of the quantity of alcohol consumed in the previous week. The ABS notes that caution should be exercised when interpreting data from surveys as accurate recall of consumption is difficult.
}

Table 4

Proportion of respondents who answered the question correctly.

\begin{tabular}{ll}
\hline $\begin{array}{l}\text { Statement } \\
\text { Average consumption of ap to } 4 \text { standard drinks per day is } \\
\text { considered 'low risk' for a male }\end{array}$ & $\begin{array}{l}\text { Proportion stating } \\
\text { correct } \\
\text { answer or less ( }\end{array}$ \\
$\begin{array}{l}\text { Average consumption of } 5-6 \text { standard drinks per day is } \\
\text { considered 'risky' for a male }\end{array}$ & 77.5 \\
$\begin{array}{l}\text { Average consumption of } 11 \text { or more standard drinks per day } \\
\text { is considered 'high risk' for a male }\end{array}$ & 81.1 \\
$\begin{array}{l}\text { Males binge drink when they drink } 7 \text { or more standard drinks } \\
\text { on any single occasion }\end{array}$ & 46.0 \\
$\begin{array}{l}\text { Males can drink } 2 \text { standard drinks in the first hour, to stay } \\
\text { within legal blood-alcohol levels for driving }\end{array}$ & 76.3 \\
$\begin{array}{l}\text { Males can drink } 1 \text { per hour after that, to stay within legal } \\
\text { blood-alcohol levels for driving }\end{array}$ & 79.3 \\
\hline $\begin{array}{l}\text { a Respondents who provided an answer that was lower than or matched the } \\
\text { correct response were considered to have answered the question correctly. }\end{array}$
\end{tabular}

Table 5

Proportion of respondents who answered the question correctly

\begin{tabular}{ll}
\hline Statement & Proportion \\
\hline $\begin{array}{l}\text { Average consumption of up to } 2 \text { standard drinks per day is considered } \\
\text { 'low' risk' for a female }\end{array}$ & 78.8 \\
$\begin{array}{l}\text { Average consumption of 3-4 standard drinks per day is considered } \\
\text { 'risky' for a female }\end{array}$ & 71.7 \\
$\begin{array}{l}\text { Average consumption of } 7 \text { or more standard drinks per day is } \\
\text { considered 'high risk' for a female }\end{array}$ & 76.6 \\
$\begin{array}{l}\text { Females binge drink when they drink } 5 \text { or more standzrd drinks on } \\
\text { any single occasion }\end{array}$ & 46.9 \\
$\begin{array}{l}\text { Females can drink } 1 \text { standard drinks in the first hour, to stay within } \\
\text { legal blood-alcohol levels for driving }\end{array}$ & 65.7 \\
$\begin{array}{l}\text { Females can drink } 1 \text { per hour after that, to stay within legal blood- } \\
\text { alcohol levels for driving }\end{array}$ & 93.5 \\
\hline
\end{tabular}

Once again, most respondents knew the levels associated with low risk alcohol consumption for females. However, the proportion of respondents who know the levels associated with low risk drinking for females was lower than it was for males. Of concern is that one in two survey respondents did not know that females binge drink when they drink five or more standard drinks on any single occasion and approximately one in three respondents did not know how much females can consume in the first hour to avoid exceeding legal blood alcohol limits.

\section{Study two results - covert observations}

Some observations were made for each person and these are now reported in Table 6.

Slightly more males were observed than females. Approximately one in ten people drank alone. There were few instances of children present and most people were observed in groups. Approximately two-thirds of the people observed were casually dressed while the remaining one-third of people wore business dress.

Drinking behaviour was observed. The number of standard drinks consumed is now reported in Table 7.

Less than one quarter of people observed did not consume any alcohol. One in three people observed consumed 2 standard drinks. Nearly one in three people observed drank at risky levels. The proportion of men drinking at risky levels was higher ( 2 in 5 men observed) than women ( 1 in 5 women observed). These rates suggest the proportion of people drinking at risky/high risk levels may be higher than previously reported by the Australian Bureau of Statistics (2006). 
Table 6

Key characteristics observed $(n=507)$.

\begin{tabular}{|c|c|c|c|c|c|c|c|}
\hline \multicolumn{2}{|l|}{ Gender } & \multicolumn{2}{|l|}{ Dress } & \multicolumn{2}{|c|}{ Group composition } & \multicolumn{2}{|c|}{ Child in company } \\
\hline Male & $56.5 x$ & Casual & $67.3 \%$ & Alone & $10.3 \%$ & Yes & $4.3 \%$ \\
\hline Female & $43.5 \%$ & Business & $32.7 \%$ & In a group & $89.7 \%$ & No & $95.3 \%$ \\
\hline
\end{tabular}

Table 7

Alcohol consumption $(n=507)$.

\begin{tabular}{|c|c|c|c|}
\hline No. of standard drinks & Proportion of people observed $\left(n=507^{2}\right)(\not)$ & Proportion of males $(n=286$ ) ( $(\%)$ & Proportion of females $(n=220)(\%)$ \\
\hline 0 & 23.1 & 14.0 & 34.5 \\
\hline 1 & 10.8 & 9.6 & 12.3 \\
\hline 2 & 34.7 & 36.7 & 32.3 \\
\hline \multicolumn{4}{|c|}{ Men and women should drink two standard drinks or less in any one day (NHMRC 2007) } \\
\hline 3 & 11.3 & 12.9 & 9.2 \\
\hline 4 & 2.5 & 3.1 & 1.9 \\
\hline 5 & 7.7 & 9.1 & 5.9 \\
\hline 6 & 3.0 & 3.4 & 2.3 \\
\hline 7 & 1.0 & 1.4 & 0.5 \\
\hline 8 & 2.8 & 4.2 & 0.5 \\
\hline 9 & 1.4 & 2.1 & 0.6 \\
\hline 10 or more & 1.7 & 3.5 & - \\
\hline
\end{tabular}

* The gender of one person was not recorded as the three observers could not agree on the person's gender.

Table 8

Alcoholic beverage types consumed on premise $(n=507)$

\begin{tabular}{llll}
\hline Beverage & Proportion consuming (\%) & Proportion of males consuming (\%) \\
\hline Beer & 53.8 & 73.1 & Proportion of females consuming (\%) \\
Wine & 13.2 & 7.0 & 29.1 \\
Spirits & 17.8 & 14.7 & 21.4 \\
Ready to drink spirits (RTD's) & 1.0 & 0.3 & 21.8 \\
\hline
\end{tabular}

An independent samples $t$-test was conducted to ascertain whether there were differences between males and females. According to the $t$-test $(p<0.001)$ males consumed more standard drinks (mean of 3.2) than females (mean of 2.3). The type of alcoholic beverages that people consumed was also observed and the results are now presented in Table 8.

Beer was the beverage of choice on premise with more than half of the people observed consuming beer. Spirits, wine and ready to drink (RTD) alcoholic beverages were consumed by proportionately less people. One in five females consumed wine and one in five females consumed spirits. Most people did not mix alcoholic drinks. Only $8 \%$ of people observed drank more than one type of alcoholic beverage.

The data were analysed by multiple regression, using as regressors drinking duration, gender, and the amount of water consumed. The multiple linear regression results are now displayed in Table 9.

The regression was a moderate fit $\left(R_{\mathrm{adj}}^{2}=53.8 \%\right)$, and the overall relationship was significant $\left(F_{4,503}=195.1, p<0.001\right)$. With other variables held constant, the number of standard drinks was positively related to drinking duration and gender and negatively related to the amount of water consumed. Further independent

Table 9

Regression analysis of drinking duration and amount of water consumed on the number of standard drinks consumed $(n=507)$

\begin{tabular}{llllll}
\hline & B & Beta & T & Sig T & R $^{2}$ \\
\hline Drinking duration & 0.001 & 0.680 & 22.342 & $p<0.001$ & \\
Amount of water consumed & -0.603 & -0.158 & -5.186 & $p<0.001$ & \\
Male & 1.061 & 0.225 & 7.414 & $p<0.001$ & \\
Constant & 0.837 & & & & 0.538 \\
\hline
\end{tabular}

sample $t$-tests were conducted to understand influences on drinking. According to independent samples $t$-tests $(p \leqslant 0.001)$ people who were in shouts or were buying drinks in rounds drank more (4.3 standard drinks) than people who were not in shouts (2.6 standard drinks).

\section{Discussion, limitations and future research directions}

Covert observations were used in this research to observe whether people enjoyed alcohol responsibly. The rationale for using observations in this study was to "record what consumers actually do, not what they claim to have done" (Boote and Mathews. 1999, p. 20). More than 500 people were observed drinking on premise, with $17.8 \%$ of people drinking at risky or high risk levels. A result of 17.8\% is higher than 2004-5 Australian Bureau of Statistics estimates (ABS, 2006a) of risky and high risk drinking. Further this result is higher than the amounts people self-reported in the survey where $11 \%$ of the sample reported drinking at risky levels. While this data may suggest there has been yet another increase in the proportion of people drinking at risky or high risk levels, or that people drink more while on-premise, it is also possible that previous estimates were impacted by the research method employed. It is possible that people under report the amount of alcohol that they drink.

Covert observations distinguish this research from previous studies concerned with alcohol consumption because rather than asking respondents to recall the quantity of alcohol consumed this research observed people consuming alcohol. Conservative assumptions were made ensuring that standard drink calculations were underestimated rather than overestimated. Observations took place in natural environments ensuring a truer picture of 
the phenomenon observed (Boote and Matthews, 1999). Covert observations offer researchers the ability to judge whether people are consuming alcohol responsibly.

This study has important limitations. The samples were not true randomly selected samples. For study 2 the observations were conducted on-premise in urban areas only. Therefore, the results, while having important implications. cannot be generalised to the entire population. Future research involving samples that are more representative of the population are encouraged to improve our understanding of alcohol knowledge and consumption. The participant observation method should be used to observe off-premise drinking. Additional on-premise observations are required with extension to alternate venues such as sporting clubs, rural and semi-rural locations in all States of Australia.

The results of the survey study are also limited to the sample and cannot be generalised to the Australian population. Future research is required to extend our understanding of alcohol knowledge using a more representative Australian sample. In this study the number of standard drinks contained in a bottle of wine was poorly understood. Specifically research seeking to understand people's knowledge of drink sizes (e.g. a restaurant serve for a glass of wine) and brands is recommended to further identify key areas of knowledge deficiency. Such endeavours can inform practice by assisting marketers, government bodies and industry associations by identifying priority areas for drinker education.

Future research endeavours should be directed towards considering the impact of various programs on on-premise drinking. Specifically, research that seeks to understand whether interventions can contribute towards real social gains, e.g. reducing the amount of alcohol consumed while on premise, is called for. For example, researchers could undertake observations to obtain baseline data. A second round of observations could then be undertaken to ascertain the impact of socially responsible initiatives such as offering one serve of water with each alcoholic beverage ordered or offering a tapas menu to patrons. Data could then be compared and contrasted to understand the impact of the initiative on the amount of alcohol consumed.

\section{Managerial and public policy implications}

A recognised CSR leaders states it "encourages the responsible enjoyment of its products by informed adults" (Fosters, 2007. p8). The results of this study illustrate that many people do not enjoy alcohol responsibly with $17.8 \%$ of people observed drinking at risky and high risk levels. Further, respondents are not adequately informed about alcohol. In this study awareness of the legal blood alcohol limit was high. while the knowledge of the number of standard drinks in a bottle of wine or a can of full-strength beer was markedly lower. The majority of observed alcohol purchases were not packaged products (e.g. purchased in labelled bottles or cans) on-premise. Given that many customers do not know how many standard drinks are in the alcoholic beverages they consume, labelling initiatives introduced with the aim of encouraging responsible drinking by informed adults are likely to have minimal impact on responsible drinking.

Alcohol marketers need to initiate two main types of activities. First, all players in the alcohol industry need to educate consumers to ensure that consumers are aware of the number of standard drinks contained in the alcohol beverages they choose to consume. Education messages can be placed on serving ware (e.g. standard drink lines on glasses or messages indicating the number of standard drinks contained) and on-premise. Second, serving practices could be altered to enable alcohol to be served in standard drink sizes. Such initiatives would reduce the need to educate consumers about the various levels of alcohol contained in different bever- ages. Serving practices, such as serving water with all alcohol beverages purchased would also assist to reduce the amount of alcohol consumed. In most cases observed water was not consumed with alcohol during drinking episodes.

Further implications for road safety bodies arise from this research. Peoples' knowledge of the number of standard drinks that could be consumed to safely drink and drive was somewhat lower than we would expect. These results suggest that road safery bodies should consider a change in focus for road safety messages. While the majority of people know the blood alcohol limit many do not know about standard drinks nor do people understand how many drinks they can safely drink before driving. Alternate messages, centring on the number of drinks per hour need to be communicated by road accident commissions. Alternatively, policy makers could consider a 0.00 blood alcohol limit as the results of this study suggest that Austrahian adults are unable to calculate whether they can drink and drive due to insufficient knowledge.

Implications for public policy arise from this research. At the time of writing this article the Australian Government was considering revising Australian Drinking Guidelines. Guidelines on the recommended number of standard drinks that Australian adults should consume each day will remain largely meaningless to Australian adults who do not understand the term standard drinks. Education is first required to improve Australian adults understanding of the term 'standard drinks'. Without this understanding people may assume that one glass of wine equals one standard drink when typical servings are closer to two standard drinks.

\section{Conclusions}

Organisations accept, as a given, the importance of being socially responsible. This was an opportune time to reassess the subject of corporate social responsibility to consider how further contributions could be made to future wellbeing. Corporate social responsibility leaders have implemented programs encouraging people to enjoy alcohol responsibly. Using current views of corporate social responsibility, we would conclude companies marketing alcohol are socially responsible based on the suite of socially responsible initiatives introduced during the past 12-24 months. Data from this study illustrates these initiatives are likely to have minimal impact in the marketplace. Further this study observed many people continuing to drink at risky levels.

While it is acknowledged that "problem drinking is a complex social issue that cannot be addressed with a single solution" (Fosters Group Limited, 2007, p8) some effort needs to be directed towards considering whether there is any market response to socially responsible initiatives before companies are deemed to be socially responsible in CSR indexes. Rather than reporting the initiatives introduced, sustainability and responsibility reports need to give consideration to the outcomes of the initiatives rather than focussing on the initiative itself. Socially responsible programs and policies that are put in place should be rigorously assessed. Adopting a corporate social performance view rather than the current corporate social responsibility view may lead to the conclusion there is considerable room for improvement before we deem key players in the Australian alcohol industry to be socially responsible.

\section{Acknowledgements}

I gratefully acknowledge the financial support provided by the NRMA ACT Road Safety Trust which made Study Two possible. Special thanks are expressed to Robin Roberts for her support and assistance with Studies One and Two. 


\section{References}

Australian Bureau of Statistics, 2006. 2006 Census Data |online|. chitp:/ www.censusdata.abs.gov.au/ABSNavigation/prenav/TopicList?prenavtabnameTopic620List\&collection=Census\&period $=2006$ breadcrumb=T\&\& navmapdisplayed $=$ true\&javascript-true\&textversion $=$ false $\&>$ (accessed 18.06.08).

Australian Bureau of Statistics. 2006. Alcohol Consumption in Australia: A snapshot Catalogue Number 4832.0 .55 .001 . August [online]. <http://www.abs.gov.au/ AUSSTATS/abs $\oplus$.nsf/mf/4832.0.55.001/> (accessed 24.01.08).

Australian Institute of Health and Welfare, 2005. 2004 National Drug Strategy Household Survey: Detailed Findings Drug Statistics Series No. 16. Catalogue Number PHE 66 [online]. <http://www.aihw.gov.au/publications/index.cfm/ ritle/10190> (accessed 18.06.08).

Barone, M.J., Miyazaki, A.D. Taylor, A.K., 2000. The influence of cause-related marketing on consumer choice. does one good turn deserve another? Joumal of the Academy of Marketing Science 28 (2), 248-262.

Baum, S., 2000. Drink driving as a social problem: comparing the attitudes and knowledge of drink driving offenders and the general community. Accident Analysis and Prevention 32. 689-694.

Berger, I.E., Kantekar, V., 1995. Increasing environmental sensitivity via workplace experiments. Journal of Public Policy and Marketing 14 (2), 205-215.

Bhattacharya, C.B., Sen, S., 2004. Doing better at doing good: when, why, and how consumers respond to corporate social initiatives. California Management Review 47 (1), 9-24.

Blythe. J.. 2006. A Very Short. Fairly Interesting and Reasonably Cheap Book About Studying Marketing. Sage Publications Ltd., London.

Boote, J., Matthews, A., 1999. Saying is one thing: doing is another: the role of observation in market research. Journal of Qualitative Market Research 2 (1). 15-21.

Brown, T.J., Dacin, P.A., 1997. The company and the product: corporate associations and consumer product responses. Journal of Marketing 61, 68-84.

Carroll, A.B., 1979. A three-dimensionai model of corporate performance. Academy of Management Review 4 (4), 497-505.

Carroll. A.B., 1991. The pyramid of corporate social responsibility: toward the moral management of organizational stakehoiders. Business Horizons 34, 39-49.

Carroll. A.B., 1999. Corporate social responsibility: evolution of a definitional construct. Business and Society $38(3), 268-295$

Carruthers, S.J., Binns, C.W., 1992. The standard drink and alcohol consumption. Drug and Alcohol Review 11, 363-370.

Craig Smith, N., 2003. Corporate social responsibility: whether or how? California Management Review 45 (4). 52-76.

Creyer, E.H., Ross Jr. W.T. 1997. The influence of firm behaviour on purchase intentions: do consumers really care about business ethics? Journal of Consumer Marketing $14(6), 421-432$.

Drumwright, M.E., 1996. Company advertising with a social dimension: the role of noneconomic criteria. Journal of Marketing 60 (4). 71-86.

Foster's Group Limited, 2007. Sustainability Report lonlinel. <http:/l www.fosters.com.au/about/sustainability.htm> (accessed 24.01.08).

Graafland, J., van de Ven. B., 2006. Strategic and moral motivation for corporate social responsibility Journal of Corporate Citizenship 22 (Summer), 111-123.

Hair. J.F., Black, B., Babin, B., Anderson, R.E., Tatham, R.L. 2006. Multivariate Data Analysis: International, sixth ed. Pearson.

Kellehear, A, 1993. The Unobtrusive Researcher. Allen and Unwin, Sydney.

Kotler, P., Lee, N. 2005. Corporate Social Responsibility: Doing the Most Good for Your Company and Your Cause, john Wiley and Sons inc. Hoboken. New jersey.

Lader, D., Goddard, E., 2006. Drinking: Adults Behaviour and Knowledge in 2006 Office for National Statistics, London, UK. [online]. <http://WwW.statistics.gov. uk/articles/journal/Drinking_2006.pdf> (accessed 24.01.08).
Lafferty, B.A. Goldsmith, R.E., 2005. Cause-brand alliances; does the cause help the brand or does the brand help the cause? Journal of Business Research (58), 423429.

Lantos, G.P., 2001. The boundaries of strategic corporate social responsibility, Journal of Consumer Marketing 18 (7). 595-630.

Licthenstein, D.R.. Drumwright, M.E., Braig. B.M., 2004. The effect of corporate socia] responsibility on customer donations to corporate-sourced nonprofits. Journal of Marketing 68, 16-32.

Luo, X.. Bhattacharya, C.B. 2006. Corporate social responsibility, customer satisfaction and market value. Journal of Marketing 70 (4). 1-18.

Maignan, I. Ferrell, O.C., 2001. Corporate citizenship as a marketing instrument: concepts, evidence and research directions. European Joumal of Marketing 35 (3/4). 3-19.

Maignan, I. Ferrell, O.C., 2004. Corporate social responsibility and marketing: an integrative framework. Journal of the Academy of Marketing Science 32 (1). 3 19

Marquez, A.. Fombrun, C... 2005. Measuring corporate social responsibility, Corporate Reputation Review 7 (4). $304-308$.

Mascarenhas, O.A.J., 1995. Exonerating unethical marketing executive behaviours; a diagnostic framework. Journal of Marketing 59 (2), 43-57.

Mikkila, M., 2003. Acceptability of operations as an indicator of corporate social performance. Business Ethics: A European Review 12 (1), 78-87.

Moir, L. 2001. What do we mean by corporate social responsibility? Corporate Governance 1 (2), 16-22.

Murray, K.B., Vogel, C.M., 1997. Using a hierarchy-of-effects approach to gauge the effectiveness of corporate social responsibility to generate goodwill toward the firm: financial versus nonfinancial impacts. Journal of Business Research 38 , $141-159$.

National Health and Medical Research Council, 2001. Australian alcohol guidelines: Health risks and benefits [online!. <http://www.nhmrcgov.au/publications/ synopses/_files/ds9.pdf $>$ (accessed 18.02.08)

National Health and Medical Research Council, 2007. Australian alcohol guidelines for low-risk drinking Australian Government [online]. <http:/l www.nhmrc.gov.au/publications/sypses/ds9syn, htm> (accessed 25.01.08).

Pride. W., Elliot, G., Rundle-Thiele, S.R., Waller, D., Paladino, A., Ferrell, O.C., 2006. Foundations of Marketing-Core Concepts and Applications. 1st Asia Pacific edn, John Wiley and Sons. Milton. Australia.

Redmond, E.C., Griffith, C.]., 2006. A pilot study to evaluate the effectiveness of a social marketing-based consumer food safety initiative using observation. British Food Journal 108 (9), 753-770.

Reis, J., Riley, W., 2002. Assessment of a computer-supported alcohol education intervention program. Health Education 102 (3), 124-132.

Rust. L., 1993. Observations: parents and children shopping together: a new approach to qualitative analysis of observational data. journal of Advertising Research 33, 65-70.

Sen. S., Bhattacharya, C.B., 2001. Does doing good always lead to doing better? Consumer reactions to corporate social responsibility. Journal of Marketing Research 38, 225-243.

Sen. S., Bhattacharya, C.B., Korshun, D., 2006. The role of corporate social responsibility in strengthening multiple stakeholder relationships: a field experiment. Journal of the Academy of Marketing Science 34, 158-166.

Sitzia, J.. Wood, N., 1998. Response rate in patient satisfaction research: an analysis of $\mathbf{2 1 0}$ published studies. International Journal for Quality in Health Care 10 . $311-317$.

Wood. D.J., 1991. Corporate social performance revisited. Academy of Management Review $16(4), 691-718$. 